\section{Sulfur sequestration, redox control and metallogeny in Earth and other planetary volcanic systems}

\section{TOBIAS P. FISCHER ${ }^{1}$ AND RICHARD W. HENLEY ${ }^{2}$}

${ }^{1}$ University of New Mexico

${ }^{2}$ Australian National University

Presenting Author: fischer@unm.edu

It has long been known that sub-volcanic gas-solid reactions involving iron play a major role in determining the redox state $\left(\mathrm{R}_{\mathrm{H}}=\log \mathrm{f}_{\mathrm{H} 2} / \log \mathrm{f}_{\mathrm{H} 2 \mathrm{O}}\right)$ of discharging gases [1]. However, the role played by calcium in these environments has only recently been recognized through high temperature gas-solid experimental studies. These studies show that $\mathrm{SO}_{2}$ in high temperature $\left(>600^{\circ} \mathrm{C}\right)$ volcanic gas mixtures efficiently reacts with plagioclase and other calcic rock-forming minerals to simultaneously deposit anhydrite and release reduced sulfur [2]. Through low anhydrite and sulfide solubilities, these reactions control the total $\mathrm{S}$ content of the gas phase and thence the redox state and $\mathrm{H}_{2} \mathrm{~S} / \mathrm{SO}_{2}$ ratio of the gas mixture. We have confirmed using multi-component thermochemical modelling of gas-solid equilibria and titration-precipitation reactions along adiabatic expansion pathways from magma to surface, that for volcanic gas mixtures of $>400{ }^{\circ} \mathrm{C}, \mathrm{R}_{\mathrm{H}}$ is primarily controlled by anorthite - pyroxene - anhydrite - sulfide reactions, irrespective of their tectonic location, state of volcanic activity and the composition of the gas mixtures released from the magma. These open system models result in compositions that are consistent with global high temperature fumarole gases (Figure 1). Sulfur sequestration is therefore an inevitable consequence of anhydrite and sulfide deposition as gas mixtures expand from a magma source to the surface (Figure 2) [3]. Such S precipitation is also consistent with observations in the many large-scale 'porphyry' $\mathrm{Cu}-\mathrm{Mo}-\mathrm{Au}$ deposits that formed in ancient volcanoes through the Phanerozoic. The loss of sulfur from the gas phase due to anhydrite and sulfide deposition also results in higher $\mathrm{C} / \mathrm{S}$ ratios relative to the gas released by sub-volcanic source magmas. This sulfur loss has implications for global volcanic $\mathrm{SO}_{2}$ emisisons, the sulfur cycle and atmosphere evolution through geologic time on Earth as well as on planets such as Mars and Venus.

[1] Giggenbach, W.F., 1987. Applied Geochemistry, 2: 141161. [2] Henley, R.W. and Seward, T.M. (2018) Rev. Mineral. Geochem. 84, 309-350. [3] Henley, R.W. and Fischer, T.P (2021) J. Volcanology and Geothermal Research 412. 107181.

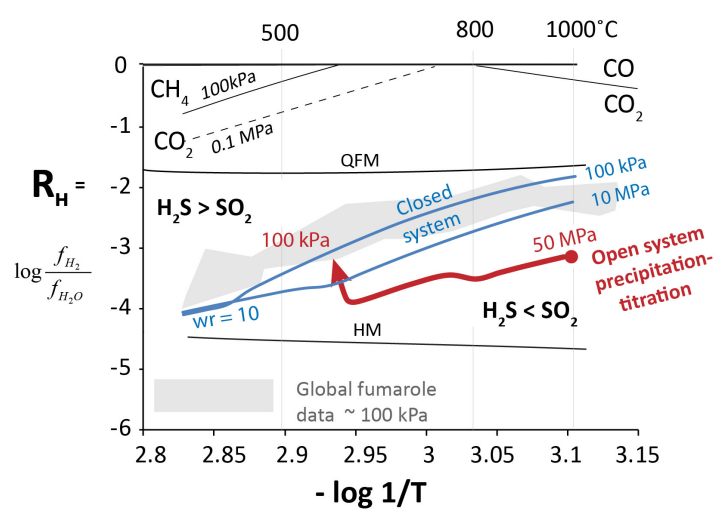

Anorthite + Fe-pyroxene $+\mathrm{SO}_{2}+\mathrm{H}_{2}+$ magnetite

$\rightarrow \mathrm{CaSO}_{4}+\mathrm{Fe}$-sulfide $+\mathrm{H}_{2} \mathrm{~S}+\mathrm{H}_{2} \mathrm{O}+$ quartz + Al-silicate

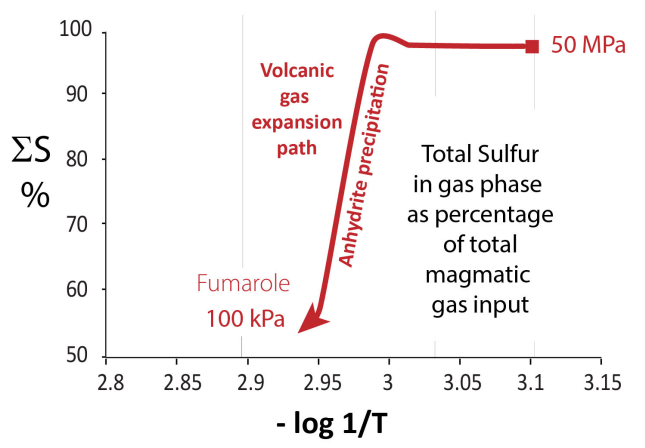

